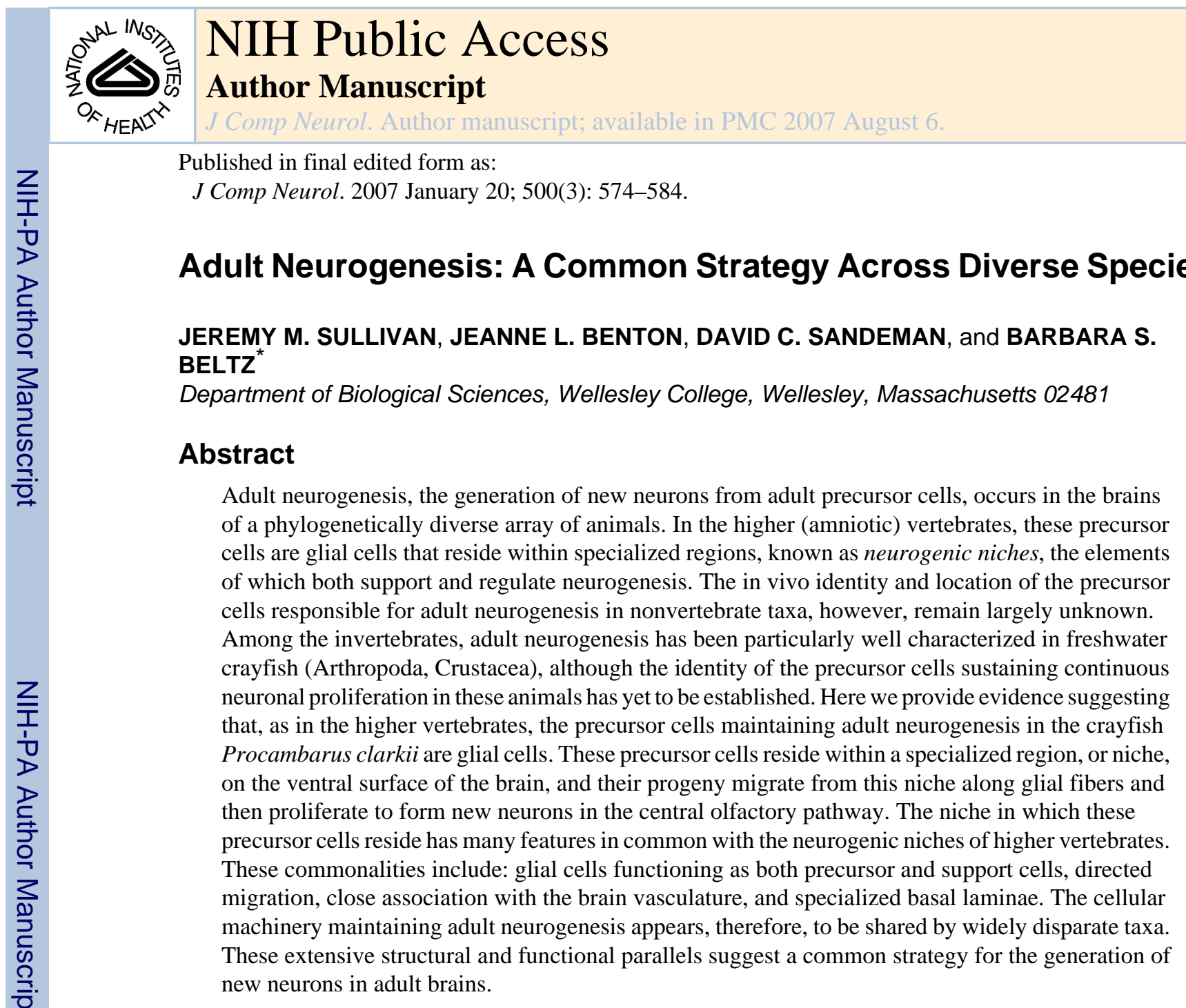

\title{
Indexing terms
}

glia; migration; neurogenic niche; olfaction; vasculature

\begin{abstract}
New neurons continue to be added to specific regions in the brains of many animals throughout adulthood (Kempermann, 2000). In vertebrates, adult-born neurons are the progeny of precursor cells residing within specialized brain regions, termed neurogenic niches (GarciaVerdugo et al., 2002;Doetsch, 2003a;Ma et al., 2005). The cellular and extracellular elements that make up these niches not only support the precursor cells structurally but also functionally regulate their activity and the development of their progeny (Song et al., 2002;Doetsch, 2003a,b;Shen et al., 2004;Ma et al., 2005). Glial cells are key components of the neurogenic niches of adult vertebrates, acting both as the precursor cells and in the support and regulation of neurogenesis (Garcia-Verdugo et al., 2002;Song et al., 2002;Doetsch, 2003a,b;Garcia et al., 2004;Seri et al., 2004;Ma et al., 2005). These cells also guide and regulate the migration of newborn cells to the regions of the brain in which they differentiate into neurons (Lois et al., 1996;Bolteus and Bordey, 2004). Additional important niche elements include a close association with the vasculature and the presence of specialized basal laminae (Palmer et al.,
\end{abstract}

*Correspondence to: Prof. Barbara Beltz, Department of Biological Sciences, Wellesley College, Wellesley, MA 02481. E-mail: bbeltz@wellesley.edu

Grant sponsor: National Institutes of Health; Grant number: 1R01 MH67157; Grant sponsor: National Science Foundation; Grant number: IBN 0344448; Grant sponsor: Maren Fellowship, Mount Desert Island Biological Laboratory. 
2000;Garcia-Verdugo et al., 2002;Mercier et al., 2002;Palmer, 2002;Doetsch, 2003a;Ma et al., 2005).

While adult neurogenesis is known to occur in a phylogenetically diverse array of animals, neurogenic niches have thus far been described only in the brains of vertebrates. Similarly, the in vivo identities of the progenitor cells maintaining adult neurogenesis in nonvertebrate animals remain largely unknown. Among the invertebrates, adult neurogenesis has been particularly well characterized in decapod crustaceans (Arthropoda, Malacostraca). As in the vertebrates, new neurons are added continuously to the brains of decapods throughout life (crayfish: Sandeman et al., 1998;Schmidt and Harzsch, 1999;Sullivan and Beltz, 2005; crabs: Schmidt, 1997,Hansen and Schmidt, 2001,2004; lobsters: Harzsch et al., 1999; spiny lobsters: Schmidt, 2001). Most of the neurons in the brains of adult decapods are born during embryonic development and are the progeny of large precursor cells, known as neuroblasts (for review see Harzsch, 2003). Decapod neuroblasts degenerate during embryonic or early postembryonic development, however, indicating that these cells are not the precursors of adult-born neurons. A permanent cell line has been established in vitro from the adult crayfish brain (Neumann et al., 2000), suggesting that the precursor cells responsible for maintaining neurogenesis in adult crayfish are located within the brain itself, although these cells have not yet been identified.

Adult neurogenesis in crayfish occurs within two populations of interneurons innervating the olfactory lobe, the functional homologue of the vertebrate olfactory bulb, and the accessory lobe, a higher order multimodal synaptic area (see Fig. 1A). The somata of these interneuronal populations form two spatially distinct groups, located lateral and medial to the lobes, known as clusters 10 and 9, respectively (terminology from Sandeman et al., 1992). Cluster 10 contains the somata of olfactory projection neurons, and cluster 9 is comprised of the somata of local interneurons (Mellon et al., 1992). Labelling with cell-cycle markers, such as the substitute nucleoside bromode-oxyuridine (BrdU), shows that cell proliferation in these areas is restricted to two regions, the lateral (LPZ) and medial (MPZ) proliferation zones (see Fig. 1A). Cells born in the LPZ contribute to cluster 10, and those born in the MPZ form part of cluster 9 (Sullivan and Beltz, 2005). Although proliferation in the LPZ and MPZ has been examined in detail, the precursor cells sustaining this mitotic activity have yet to be identified.

Here we provide evidence suggesting that the precursor cells maintaining life-long proliferation in the LPZ and MPZ of the crayfish Procambarus clarkii are glial cells residing within a specialized niche on the ventral surface of the brain. This niche possesses remarkable structural and functional parallels with the neurogenic niches of adult vertebrates. Glia within the crayfish niche appear to act as both precursor and support cells and are in close association with the vasculature and specialized basal laminae. The striking similarities in the cellular machinery maintaining adult neurogenesis in the brains of crayfish and higher vertebrates suggest a common strategy across animal phyla for generating new neurons in adult brains. Some of this work has appeared previously in abstract form (Sullivan et al., 2005).

\section{MATERIALS AND METHODS}

\section{Animals}

Male and female crayfish, Procambarus clarkii (Malacostraca, Decapoda, Astacidae), were obtained from Carolina Biological Supply Company (Burlington, NC) and maintained in aquaria with artificial freshwater and a light:dark cycle of 12:12 hours.

\section{Antibodies}

The following primary antibodies were used: monoclonal mouse anti-Drosophila synapsin (1:50; a gift from Dr. E. Buchner; No. SYNORF1), monoclonal rat anti-5-bromo-2'- 
deoxyuridine (BrdU; 1:50; Accurate Chemical, West-bury, NY; No. OBT0030G), monoclonal mouse anti-BrdU (1:50; BD Biosciences Pharmingen, San Jose, CA; No. 347580), polyclonal rabbit anti-SIFamide (1:12,000; a gift from Dr. A. Yasuda), monoclonal mouse antiallatostatin [1:10; Developmental Studies Hybridoma Bank (DSHB), Iowa City, IA; No. 5F10], polyclonal rabbit antiorcokinin (1:5,000; a gift from Dr. H. Dircksen), monoclonal mouse antiglutamine synthetase (1:100; BD Biosciences Pharmingen; No. 610517), polyclonal rabbit antiphosphohistone H3 (Thr11; 1:200; Upstate Biotechnology, Lake Placid, NY; No. 07-492), monoclonal mouse anti-MCM2-7 (1:25; a gift from Dr. A. Schwacha; No. AS1.1), monoclonal rat anti- $D N$-cadherin (1:10; DSHB; No. DN-E8), monoclonal mouse anti- $\beta$-tubulin (1:10; DSHB; No. E7), and monoclonal mouse anti-Elav (1:10; DSHB; No. Elav-9F8A9).

In singly labelled preparations, these primary antibodies were labelled with goat anti-mouse Alexa 488, goat anti-rabbit Alexa 488, and goat anti-rat Alexa 488 secondary antibodies (1:50; Molecular Probes, Eugene, OR). In double-labelled preparations, donkey anti-mouse Cy5, donkey anti-rabbit $\mathrm{Cy} 2$, and donkey anti-rat Cy2 secondary antibodies were used (1:100; Jackson Immunoresearch, West Grove, PA).

\section{Antibody characterizations}

The mouse anti-Drosophila synapsin antibody (SYN-ORF1) was raised against a GSTsynapsin fusion protein and recognizes at least four synapsin isoforms $(\sim 70,74,80$, and 143 kDa) in Western blots of Drosophila head homogenates (Klagges et al., 1996). This antibody stains a single band at $\sim 75 \mathrm{kDa}$ in Western blot analyses of $P$. clarkii brain homogenate (J. Sullivan, unpublished result). The rat anti-BrdU antibody was raised against BrdU. This antibody reacts with BrdU but does not cross-react with iododeoxyuridine (IdU; Burns and Kuan, 2005). The mouse anti-BrdU antibody was raised against a conjugate of iodouridine and ovalbumin and is highly specific for BrdU and IdU (Gratzner, 1982). Control experiments in P. clarkii showed that, after exposure of animals to BrdU, both the mouse anti-BrdU and the rat anti-BrdU antibodies labelled cells in the brain proliferation zones but that labelling in these regions after exposure of animals to IdU was observed only with the mouse anti-BrdU antibody (J. Benton, unpublished results), thus confirming the specificities of these two antibodies. The rabbit anti-SIFamide antibody was raised against the SIFamide peptide (GYRKPPFNGSIFamide) conjugated to bovine serum albumin (BSA; A. Yasuda, unpublished), and staining with this antiserum in $P$. clarkii is colocalized with in situ hybridization for the mRNA for the same neuropeptide (Yasuda et al., 2004; Yasuda-Kamatani and Yasuda, 2006). The mouse antiallatostatin antibody was raised against allatostatin 7 (the synthetic sequence APSGAQRLYGFGLamide) of the cockroach Diploptera punctata (DippuAST 7; allatostatin I) N-terminal coupled to BSA (Stay et al., 1992). Immunoreactivity in the cockroach brain and corpora allata-corpora cardiaca was eliminated by preadsorption of the antibody with the synthetic peptide (Stay et al., 1992). The brain of $P$. clarkii contains 27 allatostatin-like peptides, all of which share a conserved C-terminal sequence (-YXFGLamide; Yasuda-Kamatani and Yasuda, 2006). Because the antigen used to generate this antibody is no longer available, additional preadsorption controls were not done for the present study. However, the conserved C-terminal sequence also is shared with allatostatin 7 of $D$. punctata, so the allatostatin antibody is likely to label several of the allatostatin-like peptides present in the brain of $P$. clarkii. The rabbit antiorcokinin antibody was raised against a thyroglobulin conjugate of [ASN ${ }^{13}$ ] orcokinin (NFDEIDRSGFGFN; Bungart et al., 1994). All staining with this antiserum in the crayfish Orconectes limosus (Malacostraca, Decapoda, Astacidae) was abolished when the diluted antibody was preincubated with $50 \mathrm{nmol}$ of the immunizing peptide (Dircksen et al., 2000). The mouse antiglutamine synthetase antibody was raised against sheep glutamine synthetase. For Western blots of $P$. clarkii brain homogenate, we find that this antibody stains a single band at $\sim 44 \mathrm{kDa}$ (J. Sullivan, unpublished result). This immunoreactive peptide has a molecular weight similar to that of glutamine synthetase 
in the brain of the spiny lobster Panulirus argus ( 42 kDa; Linser et al., 1997). The rabbit antiphosphohistone $\mathrm{H} 3$ (Thr 11) antibody was raised against a synthetic peptide ARKS[pT] GGKAPRKQLC, in which pT corresponds to phosphothreonine 11 of human histone H3, conjugated to keyhole limpet hemocyanin (Upstate Biotechnology). Phosphorylation of histone $\mathrm{H} 3$ at Thr11 occurs from prophase to early anaphase (Preuss et al., 2003), thus making this antibody an M-phase marker. Because the immunizing antigen was not available, preadsorption controls were not done as part of the present study. Western blots of $P$. clarkii brain homogenate showed no specific staining with this antibody (J. Sullivan, unpublished result), which most likely is due to the low abundance of the histone $\mathrm{H} 3$ antigen in the mature brain. The mouse anti-MCM2-7 antibody was raised against the Walker B box (IDEFDKMD) on all of the MCM2-7 proteins of yeast (Klemm and Bell, 2001;Schwacha and Bell, 2001). This antibody has been shown to cross-hydrolyze with the MCM2-7 proteins of invertebrate species, including Drosophila (Claycomb et al., 2002). Expression of the MCM27 proteins is restricted to the G1 phase of the cell cycle (Cvetic and Walter, 2006). Because this antibody is no longer available, confirmatory specificity studies were not done in $P$. clarkii. The rat anti- $D N$-cadherin antibody was raised against a fusion protein representing cadherin repeats 2-8 of the extracellular domain of Drosophila N-cadherin (Iwai et al., 1997). This antibody stains a single band at $\sim 250 \mathrm{kDa}$ in Western blots of $P$. clarkii brain homogenate (J. Sullivan, unpublished result). The mouse anti- $\beta$-tubulin antibody was raised against a $\beta$-tubulin-galactosidase/ftz fusion protein. This antibody stains a single band at $\sim 55$ $\mathrm{kDa}$ in Western blots of $P$. clarkii brain homogenate (J. Sullivan, unpublished result). The mouse anti-Elav antibody was raised against the Drosophila Elav, a neuronal RNA-binding protein (Robinow et al., 1988). Evidence suggests that Elav-like RNA-binding proteins have been evolutionarily conserved in metazoans (Yao et al., 1993), but they have yet to be characterized in crustaceans. The identity of the antigen in the crayfish brain to which the antiElav antibody binds is therefore unknown. Preliminary experiments showed that this antibody revealed previously undescribed anatomical features of the crayfish brain. Therefore, the antibody was used in this study as a histological reagent, rather than as a specific marker of an Elav-like protein.

\section{Immunocytochemical labelling}

Brains were dissected from crayfish in cold crayfish saline (mM: $205 \mathrm{NaCl}, 5.4 \mathrm{KCl}, 34.4$ $\mathrm{CaCl}_{2}, 1.2 \mathrm{MgCl}_{2}, 2.4 \mathrm{NaHCO}_{3}, \mathrm{pH} 7.4$ ) and then fixed either overnight at $4^{\circ} \mathrm{C}$ in $4 \%$ paraformaldehyde in $0.1 \mathrm{M}$ phosphate buffer (PB; synapsin, BrdU, SIFamide, allatostatin, orcokinin, glutamine synthetase, phosphohistone $\mathrm{H} 3, \beta$-tubulin, Elav) or for 1 hour on ice in methanol/formalin (9:1, v:v; MCM2-7, DN-cadherin). Subsequently, preparations were rinsed for 4 hours in PB, suspended in 6\% Noble agar (Difco, Detroit, MI), and sectioned at $100 \mu \mathrm{m}$. Tissue sections were rinsed in PB containing 0.3\% Triton X-100 (PBTx) for 2 hours and incubated overnight at $4{ }^{\circ} \mathrm{C}$ in the primary antibodies. After incubation in the primary antibodies, sections were rinsed for 4 hours in PBTx and then incubated overnight in the appropriate secondary antibodies. Some sections were also counterstained with the nuclear stain propidium iodide ( $25 \mu \mathrm{g} / \mathrm{ml}$ in PB; Sigma, St. Louis, MO) for 15 minutes. Subsequently, sections were rinsed for 2 hours in PBTx and mounted in Gelmount (Biomeda, Foster City, CA).

\section{In vivo BrdU labelling}

Proliferating cells were labelled by using the thymidine analogue BrdU. Crayfish were exposed to BrdU (Sigma) by placing them in solutions of the substitute nucleoside $(2 \mathrm{mg} / \mathrm{ml})$ for periods ranging from 4 hours to 4 weeks. During long-term BrdU exposures, solutions were refreshed every $2-3$ days. Brains were fixed and processed for immunostaining as described by Sullivan and Beltz (2005). 


\section{Pulse-chase BrdU experiments}

Crayfish were initially exposed to $\mathrm{BrdU}(2 \mathrm{mg} / \mathrm{ml})$ for 10 hours. Brains were removed and fixed from animals immediately after BrdU exposure ( $n=9$ hemibrains) and at 6 days ( $n=16$ hemibrains) and 12 days ( $\mathrm{n}=16$ hemibrains) after exposure. Preparations were then processed for BrdU and glutamine synthetase immunocytochemistry, as described by Sullivan and Beltz (2005), and the numbers and distribution of BrdU-labelled cells within the glial tracts compared among the different time points. Initially, the total numbers of BrdU-labelled cells within the tracts were counted. The effect of time on the numbers of labelled cells within the tracts was then analyzed by using one-way analysis of variance (ANOVA). Post hoc pairwise comparisons were then made between groups via $t$-test. To examine the distribution of the labelled cells within the tracts, the total length of the tract spanning from the MPZ to the LPZ (se Fig. 1A) was first measured. The entire tract was then divided into percentiles, with the margin of the MPZ designated $0 \%$ and that of the LPZ as $100 \%$. The number of labelled cells within each $10 \%$ of the tract was then counted.

\section{Double nucleoside analogue-labelling experiments}

Crayfish were exposed initially to BrdU $(2 \mathrm{mg} / \mathrm{ml})$ for 6 hours. Animals were then rinsed several times in fresh water and placed in individual aquaria for 6 days. Subsequently, the crayfish were placed in solutions of IdU $(2 \mathrm{mg} / \mathrm{ml})$ for 6 hours. Brains were removed from the animals and fixed, processed, and mounted as described above. This double-labelling method is based on the different affinities of two anti-BrdU antibodies (Burns and Kuan, 2005): a mouse anti-BrdU antibody that recognizes both BrdU and IdU and a rat anti-BrdU antibody that recognizes only BrdU. Because of the different affinities of these primary antibodies, the application of the appropriate second antibodies results in double labelling of cells that have incorporated BrdU and single labelling of cells that incorporated only IdU.

\section{Intracellular staining of individual glial cells}

Intracellular staining of cells with Lucifer yellow $\mathrm{CH}$ (Sigma) was performed as described by Sullivan et al. (2000).

\section{Dye injections into the brain vasculature}

The dorsal artery to the crayfish brain was exposed, cannulated, and perfused with chilled crayfish saline in a semiintact brain preparation, as described by Sandeman et al. (1995). The brain was initially perfused with saline for several minutes to flush the hemolymph from the brain and prevent the blockage of fine brain capillaries through clotting. Subsequently, the input to the cannula was switched to a sidearm containing a concentrated solution of dextran tetramethylrhodamine 3,000 MW (Micro-Ruby; Molecular Probes), which was perfused into the brain over several minutes. Brains were then fixed overnight at $4^{\circ} \mathrm{C}$ in $4 \%$ paraformaldehyde and sectioned, processed, and mounted as described above.

\section{Confocal microscopy and image processing}

Specimens were viewed with a Leica TCS SP laser scanning confocal microscope equipped with argon, krypton, and helium-neon lasers. Serial optical sections were taken at intervals of $1 \mu \mathrm{m}$ and saved as both three-dimensional stacks and two-dimensional projections. Images were processed to adjust brightness and contrast in Adobe Photo-shop 7.0 (Adobe Systems).

\section{RESULTS}

\section{Newborn cells in the LPZ and MPZ differentiate into neurons}

To examine the differentiation of newborn cells in the LPZ and MPZ, crayfish were exposed to BrdU for 8 days to label large numbers of newborn cells and then left for a period of 6 months 
to allow these cells to differentiate. The brains of these animals were then labelled immunocytochemically for BrdU and for neurotransmitters known to be expressed by olfactory interneurons in P. clarkii (allatostatin-like peptide, orcokinin, SIFamide; Yasuda-Kamatani and Yasuda, 2006). Subsequently, brains were examined for the presence of double-labelled (BrdU + neurotransmitter) somata within clusters 10 and 9.

Double-labelled somata were observed in both cluster 10 and cluster 9 (Fig. 1B-D), indicating that adult-born cells in both the LPZ and the MPZ differentiate into neurons. BrdU-labelled cells in cluster 10 contain SIFamide immunoreactivity (Fig. 1B), whereas newborn cells in cluster 9 differentiated into neurons expressing orcokinin (Fig. 1C) or allatostatin-like peptide (Fig. 1D).

\section{The LPZ and MPZ are contacted by the processes of a specialized population of glial cells}

Immunocytochemical labelling with the glial marker glutamine synthetase (Linser et al., 1997; Sullivan and Beltz, 2005;Allodi et al., 2006) revealed that both the LPZ and the MPZ are targeted by the processes of a hitherto undescribed population of glial cells (Fig. 2A-C). These cells differ from other glia in the brain in their close proximity to one another and in the fasciculation of their processes into tracts (Fig. 2). The somata of these cells are densely packed into an oval-shaped cluster on the ventral surface of the brain (Fig. 2C-G). Each soma within this cluster is glutamine synthetase-immunoreactive, indicating that all of these cells express glial features (Fig. 2D-F). Lateral and medial subpopulations within the cluster are grouped around a circular, unlabelled region (Fig. 2D-F). Intracellular dye fills of individual glial cells show them to be bipolar, with short processes projecting to the central, unlabelled region in the cluster and longer processes that fasciculate to the form the tracts projecting to the LPZ and MPZ (Fig. 2G). Glia with somata in the lateral region of the cluster project to the LPZ, whereas glia in the medial region contribute processes to the tract projecting to the MPZ.

To further characterize the glial soma cluster, we examined its association with the brain vasculature and with specialized basal laminae, both of which are important structural and functional elements of the neurogenic niches of adult mammals. Preliminary experiments showed that the mouse anti-Elav antibody labelled the region of the glial soma cluster surrounding the central, unlabelled area (Fig. 3A,B). This antibody proved a useful marker for demarcating the border of the central, unlabelled region of the glial cluster and was used as such, rather than as a specific marker of an Elav-like protein.

Labelling of the crayfish brain vasculature via dextran injections into the dorsal artery resulted in strong labelling of the central region of the glial cluster (Fig. 3C). This region, to which the short processes of the glia project (Fig. 2G), is therefore confluent with the brain vasculature. Consequently, we have named this region the vascular cavity.

To examine the distribution of basal laminae in the crayfish brain, we used an antibody against $\mathrm{N}$-cadherin, a cell adhesion molecule expressed in some vertebrate basal laminae (CifuentesDiaz et al., 1994). Labelling with this marker was observed throughout the brain, primarily of basal laminae separating synaptic areas and adjacent soma clusters (Fig. 3D, inset). In addition, $\mathrm{N}$-cadherin-like labelling was found within the glial cluster surrounding the vascular cavity. In contrast to the simple, sheet-like structure of basal laminae in the remainder of the brain, the lamina within the cluster is a complex, spherical, latticed structure (Fig. 3D,E).

\section{The glial soma cluster is a proliferative region}

Short (4-24 hours) exposure to BrdU rarely yielded labelled cells within the cluster (data not shown). In contrast, longer (10-14 days) exposure times reliably labelled 1-2 cells in both the medial and the lateral subpopulations of the cluster (Fig. 4A,B). These cells were also labelled 
with an M-phase marker [phosphohistone H3 (Thr11); Preuss et al., 2003], indicating that they undergo mitosis (Fig. 4B, inset). Exposure times of 3-4 weeks did not result in an increase in the number of BrdU-labelled cells. The length of time required to label these cells with BrdU implies that they are relatively quiescent, as are the precursor cells in the neurogenic niches of adult vertebrates (Morshead et al., 1994;Maslov et al., 2004). Quiescence is a common characteristic of precursor cells, particularly stem cells, which may rest in G1 phase of the cell cycle for several days between cell divisions (Morshead et al., 1994;Maslov et al., 2004).

Indeed, we routinely labelled 1-2 cells in each subpopulation of the glial soma cluster by using a G1 phase-specific marker (MCM2-7; Cvetic and Walter, 2006; Fig. 4C,D). Together, these results demonstrate that the glial cluster contains a small number of mitotically active cells and that these cells exhibit in vivo properties of precursor cells.

\section{The glial tracts are migratory pathways to the LPZ and MPZ}

Double labelling with BrdU and glutamine synthetase revealed that BrdU-labelled cells also occur along the lengths of the glial tracts projecting to the LPZ and MPZ (Fig. 5A,B), suggesting that many of the cells within the tracts are mitotically active. This arrangement suggested that the glial tracts might represent migratory pathways from the glial cluster to the two proliferation zones. To determine whether cells do, in fact, migrate along the tracts, we exploited their mitotic activity and the relatively long cell cycle times (>120 hours) of adult decapod crustaceans (Schmidt, 2001) to label and examine these cells over several days. Cells within the tracts were labelled by using a 10-hour exposure to BrdU. The numbers and distributions of cells within the glial tracts were then compared immediately after exposure to BrdU and at 6 and 12 days after exposure. The total number of labelled cells within the tracts decreased significantly at both $6(P<0.01, t$-test) and $12(P<0.0001, t$-test $)$ days (Fig. 5C-E). In most of the animals at day 12 ( $\mathrm{n}=10$ of 16 hemibrains), no labelled cells were observed in the tracts outside the regions immediately adjacent to the proliferation zones, and, in two of these animals, no labelled cells were present in the tracts. Plots of the distribution of labelled cells along the tracts show that, immediately after exposure, cells are arranged along the entire length between the LPZ and the MPZ, with numbers increasing toward the proliferation zones (Fig. 5F). This distribution profile is repeated on days 6 and 12, although with increasingly fewer cells, which is consistent with the idea that cells are leaving the tracts and entering the proliferation zones. We also showed that a new population of dividing cells replaces those leaving the tracts by using a double nucleoside analogue-labelling technique (Burns and Kuan, 2005). Animals were exposed initially to BrdU and 6 days later to IdU. We then compared the distributions within the tracts of cells labelled with the two substitute nucleosides. While IdU-labelled cells were observed along the tracts, BrdU-labelled cells occurred only in the regions of the tracts adjacent to the proliferation zones (Fig. 6), suggesting that we are observing directed migration toward the lateral and medial proliferation zones. Accordingly, we have named these tracts the lateral and medial migratory streams (LMS, MMS).

\section{DISCUSSION}

Although neuronal proliferation and its regulation have been examined in detail in adult decapod crustaceans (for review see Beltz and Sandeman, 2003), the identity of the precursor cells sustaining this life-long mitotic activity has remained elusive. In the present study, we show that the two proliferation zones in the brain of adult crayfish P. clarkii, the LPZ and MPZ, are contacted by a specialized population of glial cells whose soma cluster forms an additional proliferative site on the ventral surface of the brain. The processes of these glial cells fasciculate to form tracts along which cells migrate from the glial soma cluster to both the MPZ and the LPZ, where proliferating cells differentiate into neurons. Together, these results suggest that cells within the glial soma cluster are the precursor cells maintaining adult neurogenesis in $P$. clarkii and that this cluster, therefore, represents a neurogenic niche. 
The vast majority of the neurons in the adult decapod central nervous system (CNS) are born during embryonic development (for review see Harzsch, 2003). These neurons are the progeny of large precursor cells, known as neuroblasts, which arise during early embryonic development and generate specific lineages of neurons before degenerating during late embryonic or early postembryonic development. There is no evidence that the embryonic neuroblasts persist beyond early postembryonic development. The identity of the cells maintaining the continuous neurogenesis observed in the LPZ and MPZ of adult decapods has therefore remained unclear. The results of the present study suggest that the precursors of adultborn neurons in $P$. clarkii are a small population of specialized glial cells residing on the ventral surface of the accessory lobe. The progeny of these cells appear to migrate along glial tracts to the LPZ and MPZ, where proliferation occurs. This arrangement suggests that these migrating cells may represent an amplification stage analogous to the transit-amplifying cells (type-C cells) of the neurogenic niches of adult mice (Doetsch, 2003b). The LPZ and MPZ of $P$. clarkii appear, therefore, to be functionally analogous to the neurogenic zones in the hippocampal regions of adult rodents, which also do not contain the precursor cells responsible for maintaining adult neurogenesis (Seaberg and van der Kooy, 2002;Bull and Bartlett, 2005). The identity and location of the precursor cells maintaining adult hippocampal neurogenesis remain unknown, although it is hypothesized that they reside outside the hippocampus and that, as in $P$. clarkii, their progeny migrate to the neurogenic zones, where they proliferate to form new neurons (Bull and Bartlett, 2005).

Comparative studies of adult neurogenesis in the higher (amniotic) vertebrates have revealed that the in vivo primary precursor cells in these animals are glial cells: astrocytes in mammals and radial glia in birds and reptiles (Garcia-Verdugo et al., 2002;Doetsch, 2003a,b;Merkle et al., 2004;Ma et al., 2005). Glial cells also play important supporting and regulatory roles within the neurogenic niches of these animals (Song et al., 2002;Doetsch, 2003a,b;Shen et al., 2004;Ma et al., 2005). Similarly, the results of the present study suggest that the glial cells located in the neurogenic niche of $P$. clarkii have diverse functions, acting as both precursor and support cells as well as directing the migration of newborn cells to the LPZ and MPZ. These glial cells differ from other brain glia in the close proximity of their soma and the fasciculation of their processes into tracts (Linser et al., 1997;Sullivan and Beltz, 2005;Allodi et al., 2006). Little is known about the cell biology of brain glia in decapods, so it remains unclear in what other ways these glial subpopulations might be distinctive. Similarly, nothing is currently known about the developmental origin of the brain glia of adult decapods. It is also not clear, therefore, whether the glial cells forming the niche arise from a lineage different from that of other brain glia. A first step toward addressing this question will be to determine the developmental stage at which the neurogenic niche is formed. These investigations will also be important in determining whether this niche contributes to the embryonic development of the brain or whether its functions are specific to adult neurogenesis.

While glial cells represent the key elements of vertebrate neurogenic niches (Doetsch, 2003b;Ma et al., 2005), basal laminae and the brain vasculature have also been recognized as important niche components (Palmer et al., 2000;Louissaint et al., 2002;Mercier et al., 2002;Palmer, 2002;Doetsch, 2003a;Shen et al., 2004;Campos, 2005). The specialized basal laminae that occur within vertebrate neurogenic niches are thought to play roles in anchoring cells and tethering modulatory factors (Mercier et al., 2002;Campos, 2005), whereas the endothelial cells lining the brain vasculature have been shown to regulate neurogenic activity within niches (Louissaint et al., 2002; Shen et al., 2004). The neurogenic niche of $P$. clarkii is also characterized by the presence of a specialized basal lamina and by a close association with the vasculature. The basal lamina within the niche of $P$. clarkii differs from basal laminae elsewhere in the brain in its complex, spherical, latticed structure. We are currently examining the fine anatomy of this structure and its relation to the niche cells, by using semithin sections and electron microscopy, to gain insights into the functional significance of these 
specializations. These anatomical investigations are also examining the fine structure of vascular cavity within the niche and its relation to the short processes of the niche glia that project to this region (see Fig. 2G). Only some of the capillaries in the brains of decapod crustaceans are lined with cells (Abbott, 1971), as in vertebrates. One of the goals of these fine structural analyses, therefore, is to determine whether such cells line the vascular cavity or whether this cavity represents a more direct interface between the blood (hemolymph) and the niche glia.

Among invertebrates, adult neurogenesis has also been examined extensively in insects (Cayre et al., 1996,2005; Scotto-Lomassese et al., 2003;Dufour and Gadenne, 2006). The CNS of insects, as in decapods, is produced developmentally by large precursor cells known as neuroblasts (Doe and Skeath, 1996;Truman and Ball, 1998), although it remains unclear whether the neuroblasts of these two arthropod groups are homologous (Whitington and Bacon, 1997; Harzsch, 2001;Scholtz and Gerberding, 2002). In contrast to the case in decapods, it has long been recognized that, in those insects in which adult neurogenesis occurs (crickets, beetles, and moths), adult-born neurons are the progeny of a small number of neuroblasts that persist into adulthood (Cayre et al., 1996,2005;Dufour and Gadenne, 2006). This marked difference in the identities of the precursor cells sustaining adult neurogenesis in these animals may reflect their greatly different life spans; insects live over days or weeks, whereas decapod crustaceans can live for years or decades (Wolff, 1978;Cooper and Uzmann, 1980). If this is so, it could suggest that the problem of maintaining neurogenesis in adult brains over extended periods may require the establishment of a new proliferative system postembryonically, differing from that responsible for the generation of the CNS during embryonic development. Furthermore, the extensive structural and functional parallels between the neurogenic niches of crayfish and higher vertebrates imply a common strategy across taxa for the production of new neurons in adult brains. Whether these parallel features represent homologies or are the result of convergence remains unknown.

In conclusion, the results of the present study suggest that the precursor cells maintaining adult neurogenesis in P. clarkii reside within a specialized region, or niche, on the ventral surface of the brain. This niche exhibits striking similarities with the neurogenic niches in the brains of adult vertebrates. Perhaps most notable is the importance of glial cells in the niches of these diverse taxa and their dual functional roles, as both precursor and support cells. The commonalities also extend to other key niche elements: directed migration, association with the vasculature, and specialized basal laminae. The cellular machinery guiding the birth and migration of adult neurons appears, therefore, to be shared by widely disparate taxa. These remarkable structural and functional parallels suggest a common strategy across animal phyla for the production of new neurons in adult brains.

\section{Acknowledgements}

We thank E. Buchner, H. Dircksen, A. Schwacha, and A. Yasuda for kindly providing antibodies; S. Allodi for discussions concerning the properties of decapod glia; G. Harris for assistance with the Western blot analyses; and P. Carey and V. Quinan for technical assistance.

\section{LITERATURE CITED}

Abbott NJ. The organization of the cerebral ganglion in the shore crab, Carcinus maenas. II. The relation of intracerebral blood vessels to the other brain elements. Z Zellforsch Mikrosk Anat 1971;120(3): 401-419.

Allodi S, Bressan CM, Carvalho SL, Cavalcante LA. Regionally specific distribution of the binding of anti-glutamate synthetase and anti-S100 antibodies and of Datura stratonium lectin in glial domains of the optic lobe of the giant prawn. Glia 2006;53:612-620. [PubMed: 16435368]

Beltz BS, Sandeman DC. Regulation of life-long neurogenesis in the decapod crustacean brain. Arthropod Struct Dev 2003;32:175-188. 
Bolteus AJ, Bordey A. GABA release and uptake regulate neuronal precursor migration in the postnatal subventricular zone. J Neurosci 2004;24:7623-7631. [PubMed: 15342728]

Bull ND, Bartlett PF. The adult mouse hippocampal progenitor is neurogenic but not a stem cell. $\mathrm{J}$ Neurosci 2005;25:10815-10821. [PubMed: 16306394]

Bungart D, Dircksen H, Keller R. Quantitative determination and distribution of the myotropic neuropeptide orcokinin in the nervous system of astacidean crustaceans. Peptides 1994;15:393-400. [PubMed: 7937311]

Burns KA, Kuan CY. Low doses of bromo- and iododeoxyuridine produce near-saturation labeling of adult proliferative populations in the dentate gyrus. Eur J Neurosci 2005;21:803-807. [PubMed: 15733099]

Campos LS. $\beta 1$ Integrins and neural stem cells: making sense of the extracellular environment. Bioessays 2005;27:698-707. [PubMed: 15954093]

Cayre M, Strambi C, Charpin P, Augier R, Meyer M, Edwards JC, Strambi A. Neurogenesis in adult insect mushroom bodies. J Comp Neurol 1996;371:300-310. [PubMed: 8835734]

Cayre M, Malaterre J, Scotto-Lomassese S, Aouane A, Strambi C, Strambi A. Hormonal and sensory inputs regulate distinct neuroblast cell cycle properties in adult cricket brain. J Neurosci Res 2005;82:659-664. [PubMed: 16247805]

Cifuentes-Diaz C, Nicolet M, Goudou D, Rieger F, Mege RM. N-cadherin expression in developing, adult and denervated chicken neuromuscular system: accumulations at both the neuromuscular junction and the node of Ranvier. Development 1994;120:1-11. [PubMed: 8119118]

Claycomb JM, MacAlpine DM, Evans JG, Bell SP, Orr-Weaver TL. Visualization of replication initiation and elongation in Drosophila. J Cell Biol 2002;159:225-236. [PubMed: 12403810]

Cooper, RA.; Uzmann, JR. Ecology of juvenile and adult Homarus. In: Cobb, JS.; Phillips, BF., editors. The biology and management of lobsters. 2. New York: Academic Press; 1980. p. 97-142.

Cvetic CA, Walter JC. Getting a grip on licensing: mechanism of stable Mcm2-7 loading onto replication origins. Mol Cell 2006;21:143-144. [PubMed: 16427002]

Dircksen H, Burdzik S, Sauter A, Keller R. Two orcokinins and the novel octapeptide orcomyotropin in the hindgut of the crayfish Orconectes limosus: identified myostimulatory neuropeptides originating together in neurones of the terminal abdominal ganglion. J Exp Biol 2000;203:2807-2818. [PubMed: 10952880]

Doe CQ, Skeath JB. Neurogenesis in the insect central nervous system. Curr Opin Neurobiol 1996;6:1824. [PubMed: 8794042]

Doetsch F. A niche for adult neural stem cells. Curr Opin Genet Dev 2003a;13:543-550. [PubMed: 14550422]

Doetsch F. The glial identity of neural stem cells. Nat Neurosci 2003b;6:1127-1134. [PubMed: 14583753]

Dufour MC, Gadenne C. Adult neurogenesis in a moth brain. J Comp Neurol 2006;495:635-643. [PubMed: 16498684]

Garcia AD, Doan NB, Imura T, Bush TG, Sofroniew MV. GFAP-expressing progenitors are the principal source of constitutive neurogenesis in adult mouse forebrain. Nat Neurosci 2004;7:1233-1241. [PubMed: 15494728]

Garcia-Verdugo JM, Ferron S, Flames N, Collada L, Desfilis E, Font E. The proliferative ventricular zone in adult vertebrates: a comparative study using reptiles, birds, and mammals. Brain Res Bull 2002;57:765-775. [PubMed: 12031273]

Gratzner HG. Monoclonal antibody to 5-bromo- and 5-iododeoxyuridine: a new reagent for detection of DNA replication. Science 1982;218:474-475. [PubMed: 7123245]

Hansen A, Schmidt M. Neurogenesis in the central olfactory pathway of the adult shore crab Carcinus maenas is controlled by sensory afferents. J Comp Neurol 2001;441:223-233. [PubMed: 11745646]

Hansen A, Schmidt M. Influence of season and environment on adult neurogenesis in the central olfactory pathway of the shore crab, Carcinus maenas. Brain Res 2004;1025:85-97. [PubMed: 15464748]

Harzsch S. Neurogenesis in the crustacean ventral nerve cord: homology of neuronal stem cells in Malacostraca and Branchiopoda. Evol Dev 2001;3:154-169. [PubMed: 11440250] 
Harzsch S. Ontogeny of the ventral nerve cord in malacostracan crustaceans: a common plan for neuronal development in Crustacea, Hexapoda and other Arthropoda? Arthropod Struct Dev 2003;32:17-37.

Harzsch S, Miller J, Benton J, Beltz B. From embryo to adult: persistent neurogenesis and apoptotic cell death shape the lobster deutocerebrum. J Neurosci 1999;19:3472-3485. [PubMed: 10212307]

Iwai Y, Usui T, Hirano S, Steward R, Takeichi M, Uemura T. Axon patterning requires DN-cadherin, a novel neuronal adhesion receptor, in the Drosophila embryonic CNS. Neuron 1997;19(1):77-89. [PubMed: 9247265]

Kempermann, G. Adult neurogenesis: stem cells and neuronal development in the adult brain. New York: Oxford University Press; 2000.

Klagges BRE, Heimbeck G, Godenschwege TA, Hofbauer A, Pflugfelder GO, Reifegerste R, Reisch D, Schaupp M, Buchner S, Buchner E. Invertebrate synapsins: a single gene codes for several isoforms in Drosophila. J Neurosci 1996;16:3154-3165. [PubMed: 8627354]

Klemm RD, Bell SP. ATP bound to the origin recognition complex is important for preRC formation. Proc Natl Acad Sci U S A 2001;98:8361-8367. [PubMed: 11459976]

Linser PJ, Trapido-Rosenthal HG, Orona E. Glutamine synthetase is a glial-specific marker in the olfactory regions of the lobster (Panulirus argus) nervous system. Glia 1997;20:275-283. [PubMed: 9262232]

Lois C, Garcia-Verdugo JM, Alvarez-Buylla A. Chain migration of neuronal precursors. Science 1996;271:978-981. [PubMed: 8584933]

Louissaint A, Rao S, Leventhal C, Goldman SA. Coordinated interaction of neurogenesis and angiogenesis in the adult songbird brain. Neuron 2002;34:945-960. [PubMed: 12086642]

Ma DK, Ming GL, Song H. Glial influences on neural stem cell development: cellular niches for adult neurogenesis. Curr Opin Neurobiol 2005;15:514-520. [PubMed: 16144763]

Maslov AY, Barone TA, Plunkett RJ, Pruitt SC. Neural stem cell detection, charaterization, and agerelated changes in the subventricular zone of mice. J Neurosci 2004;24:1726-1733. [PubMed: 14973255]

Mellon, DeF; Alones, V.; Lawrence, MD. Anatomy and fine structure of neurons in the deutocerebral projection pathway of the crayfish olfactory system. J Comp Neurol 1992;321:93-111. [PubMed: 1377206]

Mercier F, Kitasako JT, Hatton GI. Anatomy of the brain neurogenic zones revisited: fractones and the fibroblast/macrophage network. J Comp Neurol 2002;451:170-188. [PubMed: 12209835]

Merkle FT, Tramontin AD, Garcia-Verdugo JM, Alvarez-Buylla A. Radial glia give rise to adult neural stem cells in the subventricular zone. Proc Natl Acad Sci U S A 2004;96:11619-11624.

Morshead CM, Reynolds BA, Craig CG, McBurney MW, Staines WA, Morassutti D, Weiss S, van der Kooy D. Neural stem cells in the adult mammalian forebrain: a relatively quiescent subpopulation of subependymal cells. Neuron 1994;13:1071-1082. [PubMed: 7946346]

Neumann T, Kaiser HE, Rath FW. A permanent cell line of the crayfish Orconectes limosus as a potential model in comparative oncology. In Vivo 2000;14:691-698. [PubMed: 11125551]

Palmer TD. Adult neurogenesis and the vascular Nietzsche. Neuron 2002;34:856-858. [PubMed: 12086632]

Palmer TD, Willhoite AR, Gage FH. Vascular niche for adult hippocampal neurogenesis. J Comp Neurol 2000;425:479-494. [PubMed: 10975875]

Preuss U, Landsberg G, Scheidtmann KH. Novel mitosis-specific phosphorylation of histone H3 at Thr11 mediated by Dlk/ZIP kinase. Nucleic Acids Res 2003;31:878-885. [PubMed: 12560483]

Robinow S, Campos AR, Yao KM, White K. The elav gene product of Drosophila, required in neurons, has three RNP consensus motifs. Science 1988;242:1570-1572. [PubMed: 3144044]

Sandeman DC, Sandeman R, Derby C, Schmidt M. Morphology of the brain of crayfish, crabs, and spiny lobsters: a common nomenclature for homologous structures. Biol Bull 1992;183:304-326.

Sandeman D, Beltz B, Sandeman R. Crayfish brain interneurons that converge with serotonin giant cells in accessory lobe glomeruli. J Comp Neurol 1995;352:263-279. [PubMed: 7721994]

Sandeman R, Clarke D, Sandeman D, Manly M. Growth-related and antennular amputation-induced changes in the olfactory centers of crayfish brain. J Neurosci 1998;18:6195-6206. [PubMed: 9698313] 
Schmidt M. Continuous neurogenesis in the olfactory brain of adult shore crabs, Carcinus maenas. Brain Res 1997;762:131-143. [PubMed: 9262167]

Schmidt M. Neuronal differentiation and long-term survival of newly generated cells in the olfactory midbrain of the adult spiny lobster, Panulirus argus. J Neurobiol 2001;48:181-203. [PubMed: 11466706]

Schmidt M, Harzsch S. Comparative analysis of neurogenesis in the central olfactory pathway of adult decapod crustaceans by in vivo BrdU-labeling. Biol Bull 1999;196:127-136.

Scholtz, G.; Gerberding, M. Cell lineage of crustacean neuroblasts. In: Wiese, K., editor. The crustacean nervous system. Berlin: Springer; 2002. p. 406-416.

Schwacha A, Bell SP. Interactions between two catalytically distinct MCM subgroups are essential for coordinated ATP hydrolysis and DNA replication. Mol Cell 2001;8:1093-1104. [PubMed: $11741544]$

Scotto-Lomassese S, Strambi C, Strambi A, Aouane A, Augier R, Rougon G, Cayre M. Suppression of adult neurogenesis impairs olfactory learning and memory in an adult insect. J Neurosci 2003;23:9289-9296. [PubMed: 14561855]

Seaberg RM, van der Kooy D. Adult rodent neurogenic regions: the ventricular subependyma contains neural stem cells, but the dentate gyrus contains restricted progenitors. J Neurosci 2002;22:17841793. [PubMed: 11880507]

Seri B, Garcia-Verdugo JM, Collado-Morente L, McEwen BS, Alvarez-Buylla A. Cell types, lineage, and architecture of the germinal zone in the adult dentate gyrus. J Comp Neurol 2004;478:359-378. [PubMed: 15384070]

Shen Q, Goderie SK, Jin L, Karanth N, Sun Y, Abramova N, Vincent P, Pumiglia K, Temple S. Endothelial cells stimulate self-renewal and expand neurogenesis of neural stem cells. Science 2004;304:1338-1340. [PubMed: 15060285]

Song H, Stevens CF, Gage FH. Astroglia induce neurogenesis from adult neural stem cells. Nature 2002;417:39-44. [PubMed: 11986659]

Stay B, Chan KK, Woodhead AP. Allatostatin-immunoreactive neurons projecting to the corpora allata of adult Diploptera punctata. Cell Tissue Res 1992;270:15-23. [PubMed: 1423517]

Sullivan JM, Beltz BS. Newborn cells in the adult crayfish brain differentiate into distinct neuronal types. J Neurobiol 2005;65:157-170. [PubMed: 16114027]

Sullivan JM, Benton JL, Beltz BS. Serotonin depletion in vivo inhibits the branching of olfactory projection neurons in the lobster deutocerebrum. J Neurosci 2000;20:7716-7721. [PubMed: 11027233]

Sullivan JM, Sandeman DC, Beltz BS. Characterization of a putative stem/progenitor cell niche in the brain of an adult invertebrate, the crayfish Procambarus clarkii. Soc Neurosci Abstr 2005;31

Truman JW, Ball EE. Patterns of embryonic neurogenesis in a primitive wingless insect, the silverfish, Ctenolepisma longicaudata: comparison with those seen in flying insects. Dev Genes Evol 1998;208:357-368. [PubMed: 9732550]

Whitington, PM.; Bacon, JP. The organization and development of the arthropod ventral nerve cord: insights into arthropod relationships. In: Fortey, RA.; Thomas, RH., editors. Arthropod relationships. London: Chapman and Hall; 1997. p. 295-304.

Wolff T. The maximum size of lobsters (Homarus; Decapoda, Nephropidae). Crustaceana 1978;34:114.

Yao KM, Samson ML, Reeves R, White K. Gene elav of Drosophila melangoster: a prototype for neuronal-specific RNA binding protein gene family that is conserved in flies and humans. J Neurobiol 1993;24:723-739. [PubMed: 8331337]

Yasuda A, Yasuda-Kamatani Y, Nozaki M, Nakajima T. Identification of GYRKPPFNGSIFamide (crustacean-SIFamide) in the crayfish Procambarus clarkii by topological mass spectrometry analysis. Gen Comp Endrocrinol 2004;135:391-400.

Yasuda-Kamatani Y, Yasuda A. Characteristic expression patterns of allatostatin-like peptide, FMRFamide-related peptide, orcokinin, tachykinin-related peptide, and SIFamide in the olfactory system of crayfish Procambarus clarkii. J Comp Neurol 2006;496:135-147. [PubMed: 16528723] 

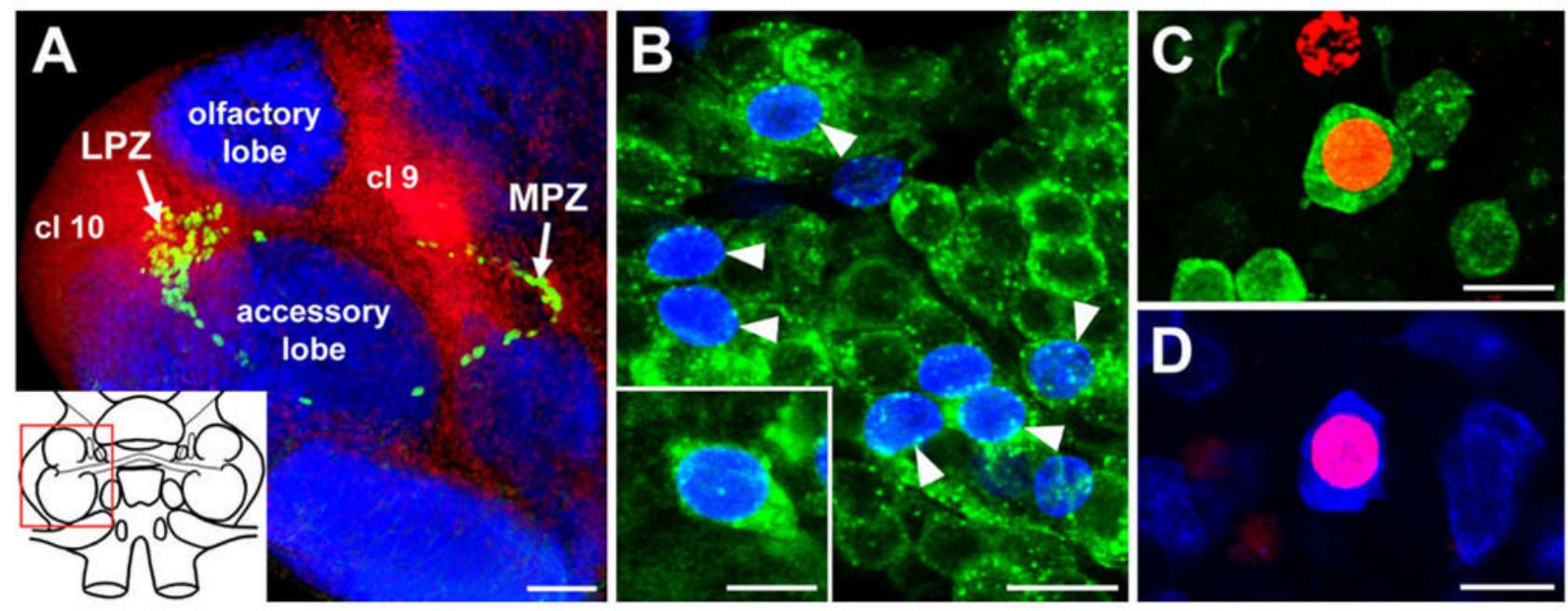

Fig 1.

Neurogenesis in the olfactory pathway of the adult crayfish brain. A: Confocal image of the olfactory and accessory lobes of $P$. clarkii in a brain labelled immunocytochemically for BrdU (green) and Drosophila synapsin (blue) and counterstained with propidium iodide (red), a marker of nucleic acids. BrdU-labelled cells can be observed within both the lateral (LPZ) and medial (MPZ) proliferation zones. The inset shows a schematic drawing of the brain, and the red box delineates the region shown. B: BrdU (blue) and SIFamide (green) immunolabelling in cluster 10 six months after the exposure of the animal to BrdU. Double-labelled cells are indicated by the arrowheads. The inset shows a higher magnification image of the soma of a double-labelled neuron. C: Double labelling of a soma for BrdU (red) and orcokinin (green) in cluster 9 of an animal exposed 6 months previously to BrdU. D: Double labelling of a cluster 9 soma for BrdU (red) and allatostatin-like peptide (blue). cl 9, Soma cluster 9; cl 10, soma cluster 10; LPZ, lateral proliferation zone; MPZ, medial proliferation zone. Scale bars $=100$ $\mu \mathrm{m}$ in $\mathrm{A} ; 20 \mu \mathrm{m}$ in $\mathrm{B} ; 10 \mu \mathrm{m}$ in inset in $\mathrm{B} ; 15 \mu \mathrm{m}$ in $\mathrm{C}, \mathrm{D}$. 

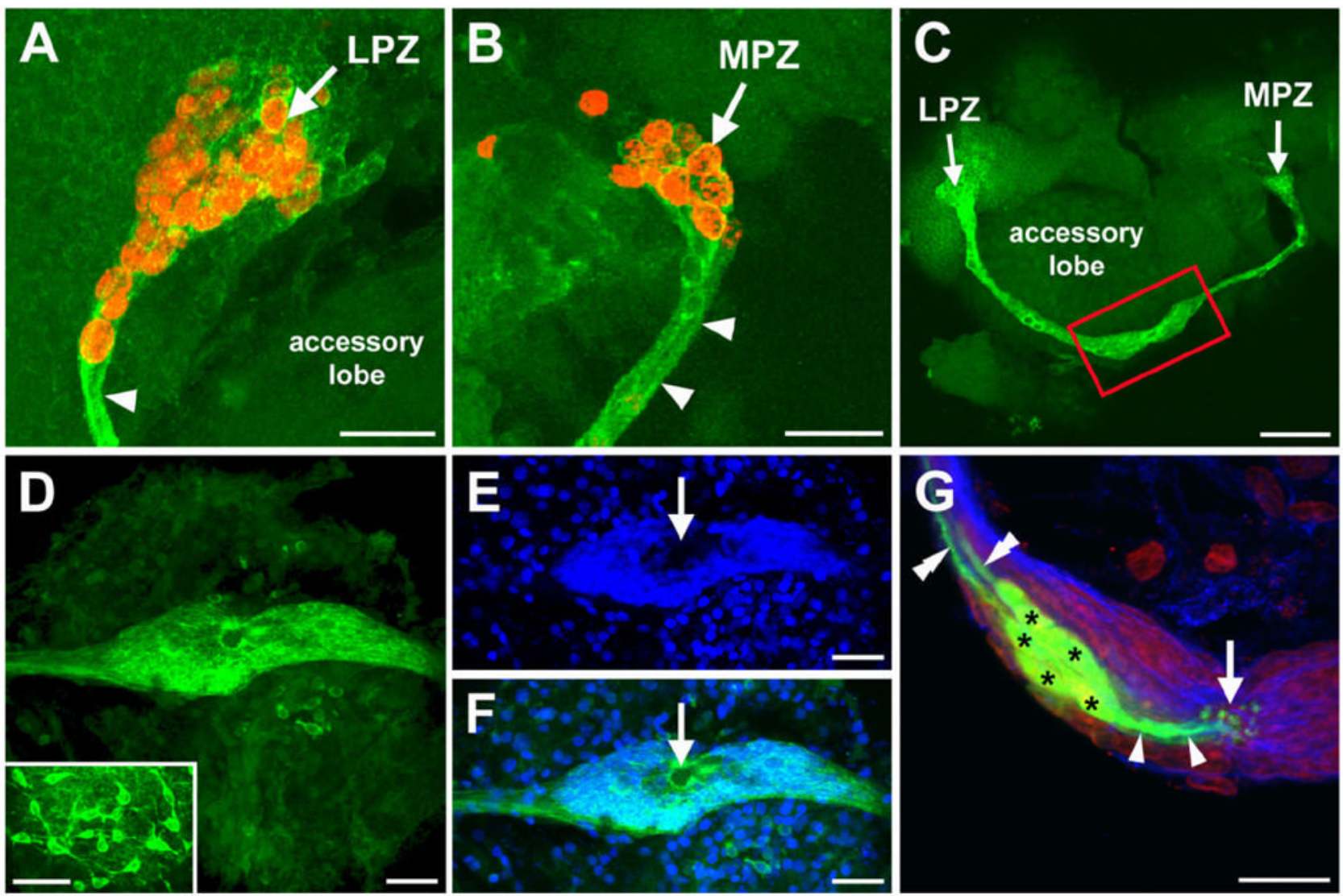

Fig 2.

The LPZ and MPZ are contacted by the processes of a specialized population of glial cells. A,B: BrdU (red) and glutamine synthetase (green) labelling of the LPZ (A) and MPZ (B). Arrowheads indicate the glutamine synthetase-immunoreactive tracts contacting the two proliferation zones. C: Glutamine synthetase labelling showing that the tracts contacting the LPZ and MPZ are contiguous and extend from an expanded region (red box) on the ventral surface of the accessory lobe. D-F: Glutamine synthetase (green) and propidium iodide (blue) labelling showing that the expanded region represents a glial soma cluster. The inset in D shows the arrangement of glia elsewhere in the brain. Arrows indicate a central, unlabelled region of the cluster. G: Intracellular dye fills (green) show that the glia (asterisks) have processes (single arrowheads) projecting to the center of the cluster (arrow) and toward the proliferation zones (double arrowheads). Glutamine synthetase (blue) and propidium iodide (red) labelling are also shown. LPZ, lateral proliferation zone; MPZ, medial proliferation zone. Scale bars $=40 \mu \mathrm{m}$ in A,B; $75 \mu \mathrm{m}$ in $\mathrm{C} ; 50 \mu \mathrm{m}$ in D-F, inset; $20 \mu \mathrm{m}$ in G. 

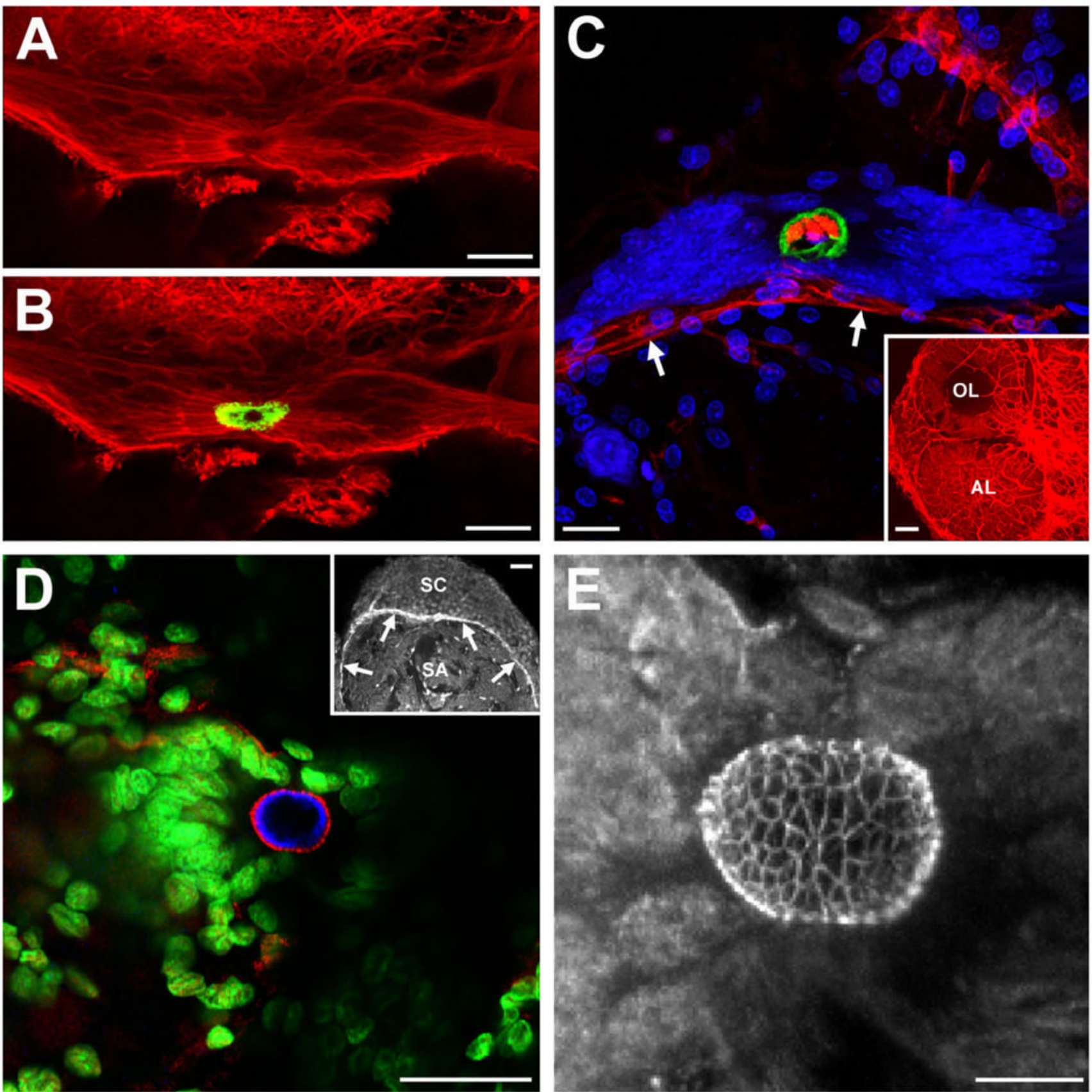

Fig 3.

The glial soma cluster is closely associated with the vasculature and specialized basal laminae. A,B: $\beta$-Tubulin (red) labelling of the glial soma cluster. The region of the cluster surrounding the central, unlabelled portion is immunoreactive to an anti-Elav antibody (green in B). C: Dextran (red) injections into the dorsal artery show that the central region of the glial cluster, outlined by anti-Elav (green) labelling, is confluent with the vasculature (arrows). We have named this region the vascular cavity. Propidium iodide (blue) labelling is also shown. The inset shows dextran labelling of the vasculature of the olfactory and accessory lobes. D: A basal lamina within the glial soma cluster labelled with an antibody to $D N$-cadherin (red). Elav (blue) and propidium iodide (green) labelling are also shown. The inset shows labelling of 
basal laminae separating a synaptic area (SA) and adjacent soma cluster (SC). E: Stacked confocal image of DN-cadherin-like labelling of a basal lamina in the glial soma cluster showing that it has a complex, latticed structure. AL, accessory lobe; OL, olfactory lobe; SA, synaptic area; SC, soma cluster. Scale bars $=25 \mu \mathrm{m}$ in A-C; $100 \mu \mathrm{m}$ in inset in $\mathrm{C} ; 40 \mu \mathrm{m}$ in $\mathrm{D} ; 50 \mu \mathrm{m}$ in inset in $\mathrm{D} ; 10 \mu \mathrm{m}$ in $\mathrm{E}$. 

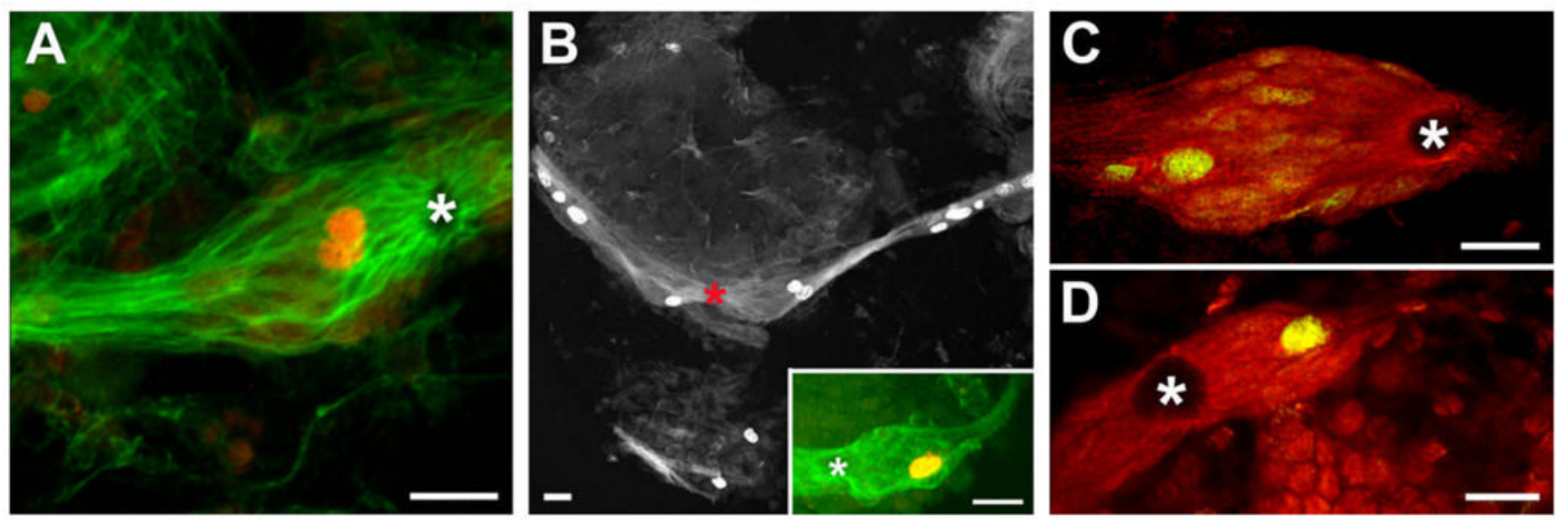

Fig 4.

The glial soma cluster contains mitotically active cells. A,B: BrdU labelling (red in A) within the glial soma cluster in animals exposed to BrdU for 2 weeks. Glutamine synthetase (green) labelling is also shown in A. The inset in B shows a cell within the cluster labelled for phosphohistone H3 (Thr11), an M-phase marker. Asterisk marks the vascular cavity. C,D: A G1-phase marker, MCM2-7 (green), labels cells in the lateral (C) and medial (D) glial subpopulations. Glutamine synthetase (red) labelling is also shown. Asterisks mark the vascular cavity. Scale bars $=25 \mu \mathrm{m}$. 

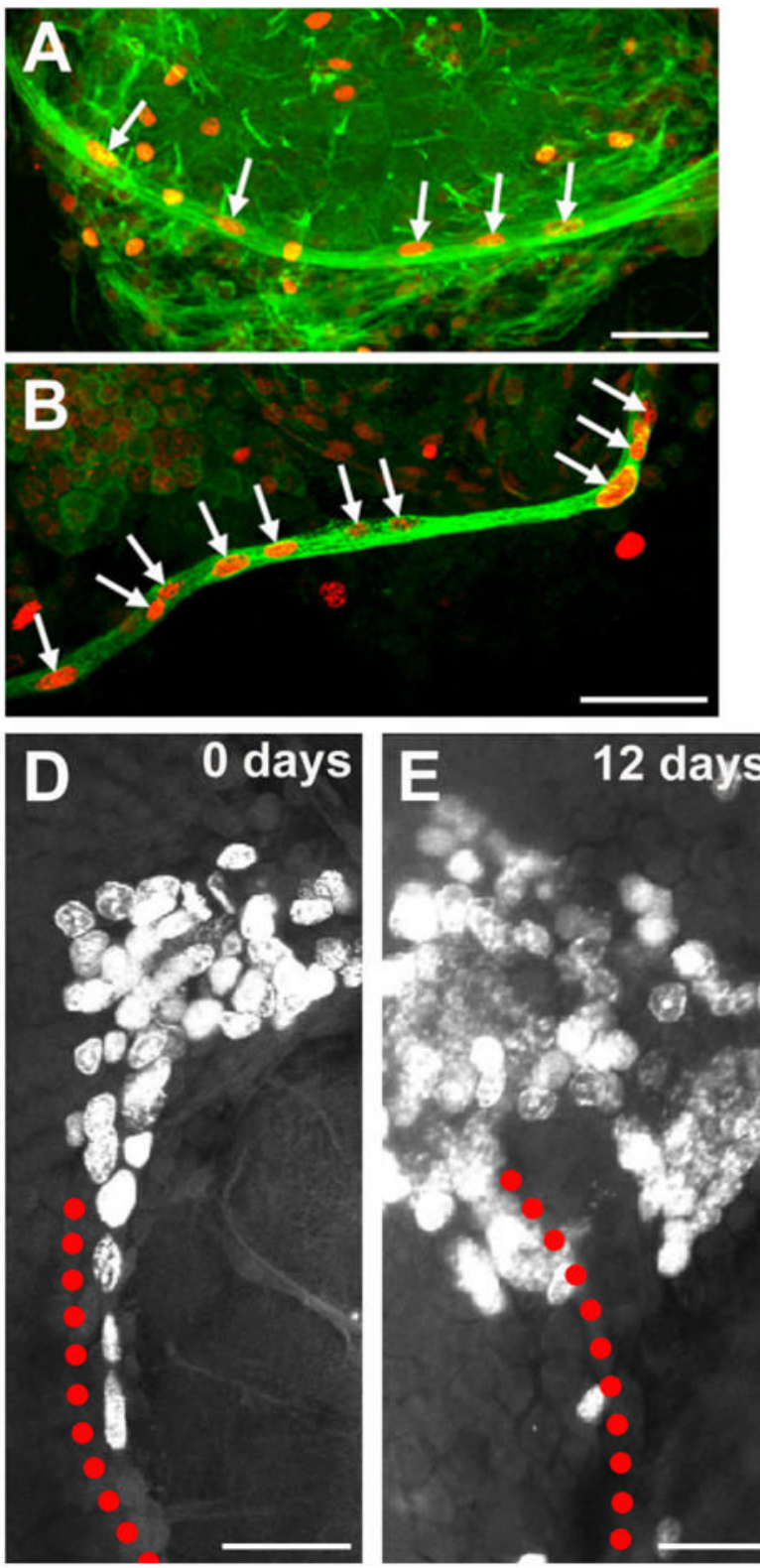

C

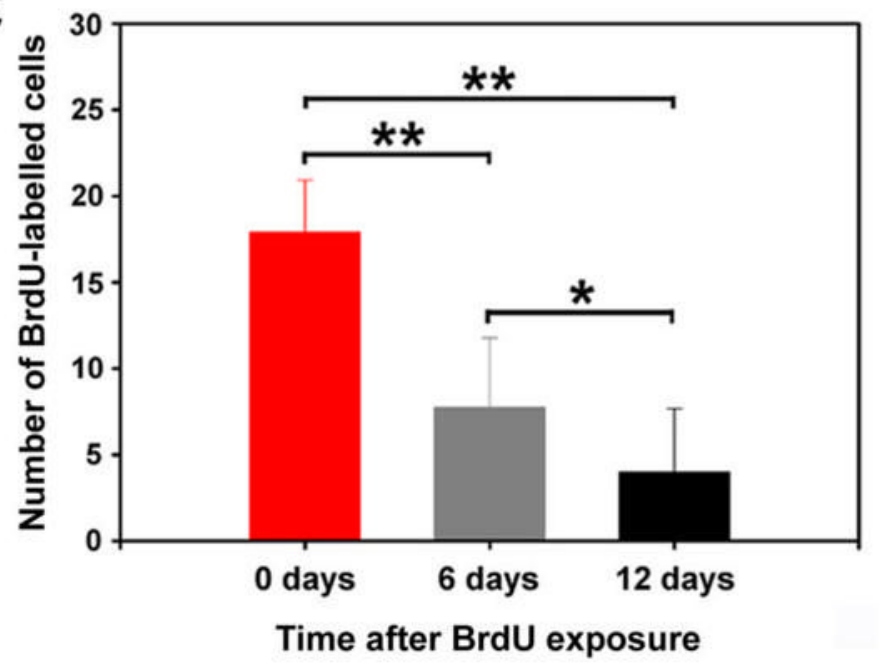

Fig 5.

The glial tracts are migratory pathways. A,B: $\mathrm{BrdU}$ (red), $\beta$-tubulin (green in A), and glutamine synthetase (green in B) labelling of the glial tracts projecting to the LPZ (A) and MPZ (B) shows that the tracts contain BrdU-labelled cells. C: Histogram showing the numbers of BrdUlabelled cells within the glial tracts 0,6 , and 12 days after exposure to $\operatorname{BrdU}$ (mean $\pm \mathrm{SD}$ ). The number of labelled cells decreased significantly over time $(P<0.0001$ by one-way ANOVA; $\mathrm{F}=41.3,38$ d.f. $)$. Significant differences between groups are marked with a single $(P<0.01$, $t$-test) or double ( $P<0.0001, t$-test) asterisk. D,E: BrdU labelling in the LPZ and associated glial tract 0 (D) and 12 (E) days after BrdU exposure. Red dots outline the path of the tract. F: Distribution of BrdU-labelled cells within the glial tracts over time. Scale bars $=50 \mu \mathrm{m}$ in $\mathrm{A}, \mathrm{B} ; 40 \mu \mathrm{m}$ in $\mathrm{D} ; 25 \mu \mathrm{m}$ in $\mathrm{E}$. 


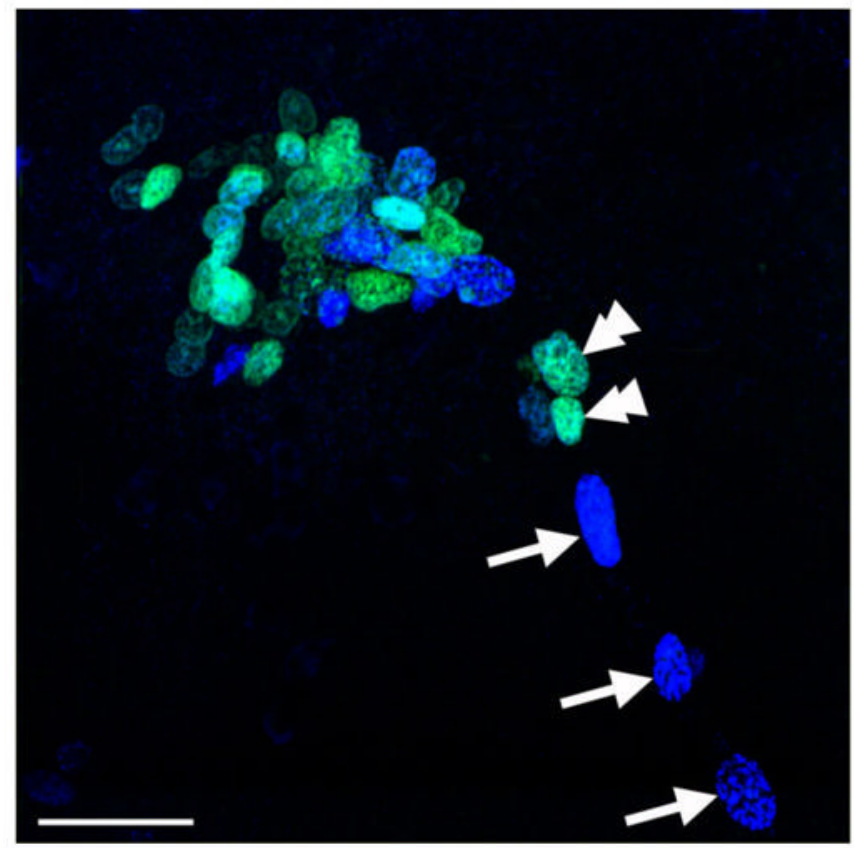

Fig 6.

The glial tracts are migratory pathways to the proliferation zones. BrdU (cyan) and IdU (blue) labelling in the LPZ and the adjacent region of the glial tract in a double-nucleoside labelling experiment in which crayfish were exposed initially to BrdU and then 6 days later to IdU. Double arrowheads show BrdU-labelled cells in the region of the glial tract immediately adjacent to the LPZ; arrows indicate IdU-labelled cells occurring along regions of the tract closer to the glial soma cluster. Scale bar $=40 \mu \mathrm{m}$. 